\title{
Interdependence of producers' adoption decision of agronomic Practices in maize production; evidence from northwest Ethiopia
}

Abebe Birara Dessie ( $\sim$ a.birara@yahoo.com )

University of Gondar

Tadie Mirie Abate

University of Gondar

Taye Melese Mekie

University of Gondar

\section{Research}

Keywords: Maize, adoption, agronomic practice, Producer, Ethiopia

Posted Date: February 14th, 2020

DOI: https://doi.org/10.21203/rs.2.20862/v2

License: (c) (i) This work is licensed under a Creative Commons Attribution 4.0 International License.

Read Full License 
The authors have withdrawn this preprint from Research Square 